|| ISSN(online): 2589-8698 || ISSN(print): 2589-868X || International Journal of Medical and Biomedical Studies

Available Online at www.ijmbs.info

PubMed (National Library of Medicine ID: 101738825)

Index Copernicus Value 2018: 75.71

\title{
OUTCOME OF SMALL-INCISION CATARACT SURGERY AND PHACOEMULSIFICATION IN TERM OF VISUAL ACUITY AND POST OPERATIVE ASTIGMATISM
}

\section{Dr Rishi Gupta, M.S.}

Fellow, Sankara Nethralaya, Kolkata

Article Info: Received 15 April 2019; Accepted 28 April. 2019

Cite this article as: Gupta, Dr. R. (2019). OUTCOME OF SMALL-INCISION CATARACT SURGERY AND PHACOEMULSIFICATION IN TERM OF VISUAL ACUITY AND POST OPERATIVE ASTIGMATISM. International Journal of Medical and Biomedical Studies, 3(4).

DOI: https://doi.org/10.32553/ijmbs.v3i4.213

Address for Correspondence: Dr Rishi Gupta, Sankara Nethralaya, Kolkata

Conflict of interest: No conflict of interest.

\section{Abstract}

Objective: To compare the outcome of Small-incision cataract surgery and Phacoemulsification in term of visual acuity and post operative astigmatism

Methods: A retrospective study carried out on 100 eyes of 100 patients from January 2017 to June 2017 at tertiary care hospital. All patients with senile cataract (up to grade IV) operated with SICS or Phacoemulsification were included. Records on all examinations including visual acuity, refraction, biometry, slit lamp biomicroscopy and fundoscopy from the period before surgery up to 6 weeks postoperatively were obtained.

Result: The present study reports clinical outcomes of Small-incision cataract surgery and Phacoemulsification up to 6 weeks. Out of 50 patients 34 (68\%) patients in the phacoemulsification group and 31 (62.\%) of 50 patients in the small-incision group had uncorrected visual acuity better than or equal to $6 / 18$ at 1 week. $41(82 \%)$ patients of the phacoemulsification group and $35(70 . \%)$ patients of the small-incision group were better than or equal to 6/18 at the 6-week follow-up for presenting visual activity. Visual acuity improved to 6/18 with best correction in 49 patients (98\%) and 48 (96\%) patients respectively. The mode of astigmatism was 0.5 diopters (D) for the phacoemulsification group and 1.5 $\mathrm{D}$ for the small-incision group, and the average astigmatism was $1.0 \mathrm{D}$ and $1.3 \mathrm{D}$, respectively.

Conclusions: Both the phacoemulsification and the small-incision techniques are safe and effective for visual rehabilitation of cataract patients, although phacoemulsification gives better uncorrected visual acuity and faster recovery

\section{Introduction:}

Cataract is the main cause of avoidable blindness all over the world. ${ }^{1}$ There are an estimated 9 to 12 million cases of blindness in India, half of which can be attributed to cataract. ${ }^{2}$ Cataract surgery forms the major workload of eye units worldwide and is a major health care expense. ${ }^{3}$ Phacoemulsification, in which an ultrasound probe emulsifies the cataractous lens through a 2.8-mm incision, has become popular in the past decade as the method of choice for cataract surgery, superseding conventional extracapsular cataract extraction (ECCE), which involves removing the lens nucleus through a large incision. It is now the technique of choice in the Western world and in many centers in developing countries like India. Both techniques use posterior chamber intraocular lens implantation. A randomized control trial in the 
United Kingdom found phacoemulsification surgery to be more effective than ECCE for rehabilitation of patients with cataract at a more economical cost. ${ }^{4}$ Manual small-incision cataract surgery, in which the nucleus is removed through a scleral tunnel through a 5.5-6.5-mm incision without the use of the phacoemulsification machine, has become popular in India. A randomized controlled trial in India found it to be more effective ${ }^{5}$ and economical ${ }^{6}$ than conventional ECCE. Both the techniques result in sutureless surgery, but phacoemulsification needs higher capital investment for the phacoemulsification machine. Moreover, the cost of consumables is also higher for phacoemulsification.

\section{Methods and Material}

This was retrospective, interventional study done after obtaining written informed consent from patients. It was study carried out on 100 eyes of 100 patients from January 2017 to June 2017 at tertiary care hospital. All patients with senile cataract (up to grade IV) operated with SICS or Phacoemulsification were included. Records on all examinations including visual acuity, refraction, biometry, slit lamp biomicroscopy and fundoscopy from the period before surgery up to 6 weeks post-operatively were obtained.

\section{Result}

The mean age was 60.8 years and 62.7 years for the phacoemulsification and small-incision groups, respectively. 34 of 50 (68\%) of the phacoemulsification group and 31 of 50 (62\%) of the small-incision group had uncorrected vision $6 / 18$ or better at the 1-week follow-up (Table 1). 41 of 50 (82\%) patients in the phacoemulsification group and 35 of 50 (70\%) patients in the small-incision group had visual acuity $6 / 18$ without any correction at the 6 -week follow-up. This improved to 49 of 50 (98\%) and 48 of 50 (96\%) patients after best possible correction (Table 2). The phacoemulsification group had 2 of $50 \%$ ) postcapsular rents, whereas the small-incision group had 3 of 50 (6\%). Both the phacoemulsification and small-incision groups had 1 patient each with iridodialysis. Iritis was more in phacoemulcification group $(10 \%)$ as compare to small-incision group (4\%). There was no of incidence of nucleus drop in both the groups. After surgery, $8(16 \%)$ patients in the phacoemulsification group had corneal edema on the first postoperative day, whereas it was 6 (12\%) for the small-incision group. None of the patients had persisting corneal edema at the 6week follow-up. Average astigmatism for the phacoemulsification group was 1.0+/- $0.7 \mathrm{D}$ and for the small-incision group it was $1.3+/-0.8 \mathrm{D}$ at 6 week post operative (Table 3). The mode for astigmatism was $0.5 \mathrm{D}$ for the phacoemulsification and $1.5 \mathrm{D}$ for the smallincision technique.

Table 1: Postoperative Visual Acuity at 1-Week Follow-up

\begin{tabular}{c|c|c|c|c}
\hline & \multicolumn{2}{|c|}{ Uncorrected VA } & \multicolumn{2}{c}{ Best corrected VA } \\
\hline Vision & Phaco & SICS & Phaco & SICS \\
\hline $6 / 6-6 / 9$ & 12 & 5 & 31 & 23 \\
$6 / 12-6 / 18$ & 22 & 26 & 14 & 18 \\
$6 / 24-6 / 60$ & 15 & 15 & 4 & 9 \\
$<6 / 60$ & 1 & 4 & 0 & 0 \\
Total & 50 & 50 & 50 & 50 \\
\hline
\end{tabular}


Table 2: Postoperative Visual Acuity at 6-Weeks Follow-up

\begin{tabular}{c|c|c|c|c}
\hline & \multicolumn{2}{|c|}{ Uncorrected VA } & \multicolumn{2}{c}{ Best corrected VA } \\
\hline Vision & Phaco & SICS & Phaco & SICS \\
\hline $6 / 6-6 / 9$ & 16 & 8 & 42 & 35 \\
$6 / 12-6 / 18$ & 25 & 27 & 7 & 13 \\
$6 / 24-6 / 60$ & 9 & 13 & 1 & 2 \\
$<6 / 60$ & 0 & 2 & 0 & 0 \\
Total & 50 & 50 & 50 & 50 \\
\end{tabular}

Table 3: Astigmatism after Surgery (at 6 weeks)

\begin{tabular}{c|c|c}
\hline Astigmatism in Diopter & Phaco & SICS \\
\hline $0-0.75$ & 21 & 13 \\
$1-1.75$ & 18 & 18 \\
$2-2.75$ & 10 & 15 \\
3 or more & 1 & 4 \\
\hline
\end{tabular}

\section{Discussion}

This is an early report comparing the 6-week results. Both the groups achieved equally good postoperative visual outcomes $(98.4 \%$ in the phacoemulsification, $98.4 \%$ in the small incision $6 / 18$ ) with best possible correction at 6 weeks. However, there was a difference in uncorrected (presenting) visual acuity, which was statistically significant at the 6-week but not at the 1-week follow-up. For everyday ambulatory vision, most patients do not use their spectacles and so rely on their uncorrected visual acuity There were more posterior capsular rents in the smallincision group, 12 (6\%) compared with 7 (3.5\%) for the phacoemulsification group, because canopener capsulotomy was done instead of complete curvilinear capsulorrhexis. But it did not result in increased poor postoperative outcome. The capsular rupture in the United Kingdom trial was $3 \%$ in the phacoemulsification surgery. ${ }^{4}$

The phacoemulsification group had a greater incidence of postoperative corneal edema on the first postoperative day, although it did not remain at the 6-week follow-up. Corneal decompensation is evident as persistent corneal edema in the first postoperative month. This was not observed in this study. A 3-year prospective randomized evaluation of intraocular lens implantation through a $3.2-\mathrm{mm}$ and a $5.5-\mathrm{mm}$ incision in Japan had a larger against-the-rule shift in the $5.5-\mathrm{mm}$ incision $(0.18 \mathrm{D}$ against-therule shift in the $3.2-\mathrm{mm}$ incision and $0.43 \mathrm{D}$ against-the-rule shift in the $5.5-\mathrm{mm}$ incision). ${ }^{8}$ Neilsen ${ }^{9}$ found it to be a 0.10 to $0.20 \mathrm{D}$ againstthe-rule shift in a $3.2-\mathrm{mm}$ incision and 0.17 to $0.35 \mathrm{D}$ in a $5.5-\mathrm{mm}$ wound. Olson and Crandall ${ }^{10}$ in a prospective masked randomized control trial found an against-the-rule shift of $-0.18 \mathrm{D}$ in a $3.2-\mathrm{mm}$ incision versus $-0.88 \mathrm{D}$ in $5.5-\mathrm{mm}$ incision (P0.001). The average astigmatism for ECCE was 2.5 D cylinder and $1.0 \mathrm{D}$ for phacoemulsification in the medical research council trial in the United Kingdom. ${ }^{4}$ This correlates with results of this study. The major limitation of the study is that the results are of the 6-week follow-up.

\section{Conclusion}

Manual small-incision cataract surgery is comparable to phacoemulsification for the rehabilitation of the patient with cataract, although the phacoemulsification technique gives better uncorrected visual acuity in a slightly larger proportion of patients at 6 weeks. Manual small-incision cataract surgery is safe and nearly as effective. Small-incision surgery does not need 
the capital investment and recurring expenditure of a phacoemulsification machine. Training in phacoemulsification surgery has a steeper learning curve than small-incision cataract surgery for surgeons trained in ECCE. It is recommended as an alternative to phacoemulsification wherever the requisite equipment and expertise are not available.

\section{References}

1. Thylefors B, Negrel AD, Pararajasegaram R, Dadzie KY. Global data on blindness. Bull World Health Organ 1995;73:115-21.

2. Dandona $L$, Dandona $R$, Naduvilath $T$, et al. Is current eyecare-policy focus almost exclusively on cataract adequate to deal with blindness in India? Lancet 1998;351:1312-6.

3. Ellwein LB, Urato CJ. Use of eye care and associated charges among Medicare population: 1991-1998. Arch Ophthalmol 2002;120;804-11.

4. Minassian DC, Rosen P, Dart JK, et al. Extra capsular cataract extraction compared with small incision surgery by phacoemulsification: a randomised trial. $\mathrm{Br} J$ Ophthalmol 2001;85: 822-9.
5. Gogate PM, Deshpande M, Wormald RP, et al. Extracapsular cataract surgery compared with manual small incision cataract surgery in community eye care setting in Western India: a randomised controlled trial. $\mathrm{Br} \mathrm{J}$ Ophthalmol 2003;87:667-72.

6. Gogate PM, Deshpande M, Wormald RP. Is manual small incision cataract surgery affordable in the developing countries? A cost comparison with extracapsular cataract extraction. Br J Ophthalmol 2003;87:843-6.

7. Oshika T, Nagahara K, Yaguchi S, et al. Three year prospective, randomized evaluation of intraocular lens implantation through 3.2 and $5.5 \mathrm{~mm}$ incisions. J Cataract Refract Surgery 1998;24:309-14.

8. Neilsen PJ. Prospective evaluation of surgically induced astigmatism and astigmatic keratotomy effect of various small selfsealing incision. J Cataract Refract Surgery 1995;21:43-8.

9. Olson RJ, Crandall AS. Prospective randomized comparison of phacoemulsification cataract surgery with a $3.2-\mathrm{mm}$ vs a $5.5-$ $\mathrm{mm}$ sutureless incision. Am J Ophthalmol 1998;125:612-20. 